Case Report

\title{
Kimura's disease - an unusual case of neck swelling
}

\section{M ridula D. Shenoy ${ }^{1}$, Chitra Y. Bhat ${ }^{2}$, Padma Shetty K. ${ }^{3}$, Jayaprakash Shetty K. ${ }^{4}$}

${ }^{1}$ Postgraduate, ${ }^{3}$ Professor, ${ }^{4}$ Professor and Head, Department of Pathology, ${ }^{2}$ Postgraduate, Department of Surgery, K.S. Hegde M edical Academy, Deralakatte, M angalore, Karnataka, India.

*Corresponding Author : M ridula D. Shenoy, 5-4-180/6(3), 'Prabhadham', Kodialguthu West, M angalore- 575003.

Mobile: +918105866651，E-mail:dr.mridulashenoy@gmail.com

Received

: 18-12-2015

Review Completed : 07-07-2016

Accepted : 14-07-2016

Keywords : Eosinophilia, Hyper IgG levels, Kimura, Lymphadenopathy

\begin{tabular}{|c|}
\hline Access this article online \\
\hline Quick Response Code \\
\hline
\end{tabular}

Abstract:

Background : Kimura's disease is an uncommon cause of lymphadenopathy in pediatric age group.

Case characteristics : Usually presents as a triad of lymphadenopathy, hyper eosinophilia and hyper IgG. Kimura's presenting as a neck swelling is rare. Intervention: Excised mass was sent for histopathology. Message: To reduce concerns of malignancy.

\section{Introduction}

Kimura's disease is an idiopathic, chronic inflammatory disease that usually affects young and middle aged Asian males ${ }^{1}$. This benign condition is characterized by a triad of painless subcutaneous masses in the head and neck, eosinophilia and markedly elevated IgG levels. The lesions are usually in deep subcutaneous tissues, more often associated with regional lymphadenopathy and salivary gland involvement ${ }^{1,2}$. Other sites of involvement include oral cavity, axilla, limbs, groin and trunk ${ }^{3}$. Renal involvement usually extra membranous glomerulonephritis is found in upto $60 \%$ of patients and proteinuria in 12 to $16 \%$ of cases $^{4,5}$. These lesions may sometimes clinically mimic a neoplasm including acute non-lymphocytic leukemia and Hodgkin's disease ${ }^{1}$.

\section{Case Report}

A 2yr old female child came with complaints of swelling in front of the neck since 2 weeks. She had no history of pain over swelling, fever, difficulty in swallowing or breathing.
Left side level 4 lymph nodes were enlarged. Systemic examination was normal. Local examination showed a solitary, oval swelling in the suprasternal notch measuring $2 \times 1 \mathrm{~cm}$. Edge of the swelling was well defined. The swelling wasnon-tender, immobile and firm in consistency.

Laboratory findings included $\mathrm{Hb}$ level of $9.7 \mathrm{~g} / \mathrm{dl}$, total leukocyte count 9200/cu.mm, platelet 3, 88,000, ESR 20. The differential count showed neutrophils $37 \%$, lymphocyte 54\% and Eosinophils 09\%. IgG levels were $1100 \mathrm{ug} / \mathrm{l}$. USG of the neck showed a well-definedhypo echoic lesion in suprasternal region and internal low level echoes with solid areas showing vascularity. Ipsilateral level 3 and 4 lymphadenopathy was seen. Impression was necrotic lymph node/cold abscess. CT of the same showed heterogeneously enhancing soft tissue density mass with central necrosis in left suprasternal region with loss of fat plane to sternocleidomastoid muscle merging with left lobe of thymus and few significant lymph nodes(bilateral) in level 1b,2,3 and ipsilateral 4 and 5 . The impression was 
likely a thymic cyst and differential diagnosis was necrotic lymph node.

An excision biopsy of the soft tissue mass was performed under General Anesthesia. 2 pale white tissue masses were sent for histopathological examination. No lymph nodes were excised.

Microscopic examination showed dense infiltration of skeletal muscle fibres and surrounding fat by sheets of eosinophils, neutrophils, plasma cells, lymphocytes, histiocytes and multinucleated giant cells among which were seen vascular proliferations lined by plump endothelial cells( figure 1) (Insert figure 1 here).

GMS and PAS stains to rule out parasites were noncontributory. The final diagnosis was given as Kimura's disease.

On follow up after $1 \mathrm{yr}$. the child seems normal.

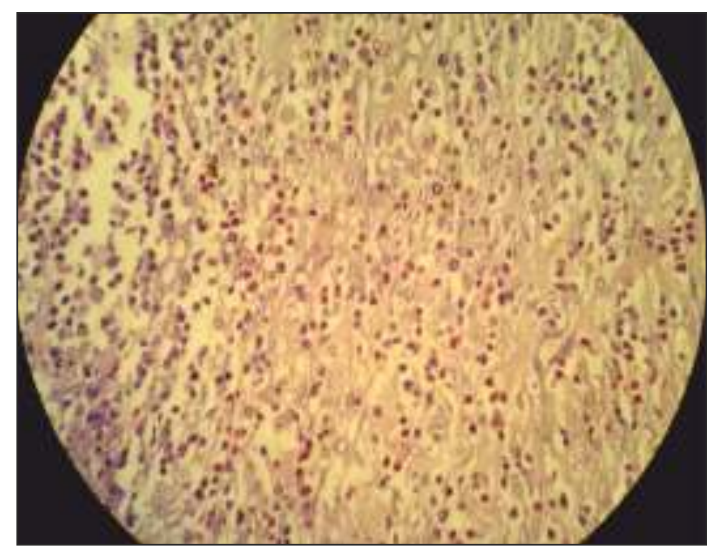

M icrograph showing Eosinophils infiltrating into skeletal muscle fibers (H\&E stain, magnification 40x)

\section{Discussion}

Kimura's disease is recognized as a benign cause of painless localized lymphadenopathy. Most cases have been reported in the $2^{\text {nd }}$ and 3 rd decade of life. Pathologically, nodular lesions usually affect lymph nodes, though occasionally skin or salivary tissues are affected. Normal tissue architecture is usually preserved, but follicular hypertrophy of the lymphatic tissue with infiltration of lymphocytes, histiocytes and large number of Eosinophils is typical ${ }^{6}$. Vascularization of germinal centres is more common but it can also be necrotic with central eosinophilia abscesses?.

The cause and pathogenesis of Kimura's disease is unclear, although allergic response, trauma and autoimmune response have been implicated as triggering factors ${ }^{8}$. It has been speculated that a viral or parasitic trigger may alter $\mathrm{T}$ cell immunoregulation or induce an IgE mediated type1 hypersensitivity resulting in the release of eosinophiliotrophic cytokines. Immunohistochemical studies performed on skin, lymph nodes and peripheral blood have shown marked proliferation of HLA-DR CD4 cells $\mathrm{s}^{2,9}$ which in turn may precipitate the high serum IgG and marked eosinophilia?.

The differential diagnosis for Kimura's disease includes Eosinophilia granulomas, acute non-lymphocytic leukemia, Mikulicz's disease Hodgkin's disease, Angioimmunoblastic lymphadenopathy, and Follicular lymphoma and Angiolymphoid hyperplasia with eosinophilia (ALHE) ${ }^{3}$. The absence of Reed Sternberg cells helps to exclude Hodgkin's disease. Although atypical histiocytosis $X$ can present with subcutaneous masses, diagnosis is made by finding the characteristic abnormal histiocytes and detecting CD1A marker. Differentiating Kimura's diseases from ALHE requires analysis of both clinical and histological features. Both diseases usually present with soft tissue masses in the head and neck region, but in ALHE, the lesions are mostly dermal or subcutaneous and not often in lymph node. ALHE is more typically seen in middle aged women and Kimura's in younger men ${ }^{10}$. Eosinophilia in peripheral blood is usually absent in ALHE and the lgG levels are normal ${ }^{8}$.

\section{Conclusion}

Kimura's disease needs to be strongly considered in any patient who present with a painless head or neck mass in association with marked eosinophilia and hyper immunoglobulinemia E. Pediatricians need to be aware of this disease as it may allow them to limit the number of laboratory tests ordered and reduce concern about the possibility of malignant disease. Regular follow up is recommended to rule out renal involvement. 


\section{References}

1. Cecen E, Kacar- Doger F, Etensel B. An extremely rare cause of generalized lymphadenopathy in children: kimura's disease. Turk J Pediatr. 2010; 52: 534-537.

2. Biradar A, Patil A V, Kotennavar M S, Venkatachalaiah M. Kimura disease: A case report. Indian J Surg. 2013; 75(1): 430-431.

3. Abuel - Haija M, Hurford M T. Kimura disease. Arch Pathol Lab Med. 2007; 131(4): 650-651

4. Abhay H, Swapna S, Darshan T, Vishal J, Gautam P. Kimura's disease: A rare cause of local lymphadenopathy. Int J Sci Stud. 2014; 2(5): 122 125.

5. B.K Prasad, R Deviprasad. Kimura's disease: An unusual case of neck mass. Indian J Otolaryngol. Head and neck Surg. 2008; 60(4): 353-355.

6. M J Chusid, A L Rock, J R Sty, H W Oechler, D J Beste. Kimura's disease:
An unusual cause of cervical tumor. Arch Dis Child. 1997; 77(2): 153154.

7. VKDik, B A Van der Wiel, W LE Varmel. Kimura's disease of the parotid glands and multiple cervical lymphadenopathy. The Journal of Medicine. 2010; 68(4): 175-177.

8. Briggs P L. Kimura disease is not angiolymphoid hyperplasia with eosinophilia: clinical and pathological correlation with literature review and definition of diagnostic criteria. Am Bras Dermatol. 2006 ; 2): 167-73.

9. Shetty A K, Beaty M W, M cGuirt WF Jr, Woods CR, Givner LB. Kimura's disease: A diagnostic challenge. Pediatrics. 2002;110(3): e39

10. Kumar V, Salini, Haridas S. Kimura's disease: An uncommon cause of lymphadenopathy. IndianJ Med PaediatrOncol. 2010; 31(3): 89-90. 